\title{
The challenges of studying visual expertise in medical image diagnosis
}

Citation for published version (APA):

Gegenfurtner, A., Kok, E., van Geel, K., de Bruin, A., Jarodzka, H., Szulewski, A., \& van Merrienboer, J. J. G. (2017). The challenges of studying visual expertise in medical image diagnosis. Medical Education, 51(1), 97-104. https://doi.org/10.1111/medu.13205

Document status and date:

Published: 01/01/2017

DOI:

10.1111/medu.13205

Document Version:

Publisher's PDF, also known as Version of record

Document license:

Taverne

Please check the document version of this publication:

- A submitted manuscript is the version of the article upon submission and before peer-review. There can be important differences between the submitted version and the official published version of record.

People interested in the research are advised to contact the author for the final version of the publication, or visit the DOI to the publisher's website.

- The final author version and the galley proof are versions of the publication after peer review.

- The final published version features the final layout of the paper including the volume, issue and page numbers.

Link to publication

\footnotetext{
General rights rights.

- You may freely distribute the URL identifying the publication in the public portal. please follow below link for the End User Agreement:

www.umlib.nl/taverne-license

Take down policy

If you believe that this document breaches copyright please contact us at:

repository@maastrichtuniversity.nl

providing details and we will investigate your claim.
}

Copyright and moral rights for the publications made accessible in the public portal are retained by the authors and/or other copyright owners and it is a condition of accessing publications that users recognise and abide by the legal requirements associated with these

- Users may download and print one copy of any publication from the public portal for the purpose of private study or research.

- You may not further distribute the material or use it for any profit-making activity or commercial gain

If the publication is distributed under the terms of Article $25 \mathrm{fa}$ of the Dutch Copyright Act, indicated by the "Taverne" license above, 


\section{The challenges of studying visual expertise in medical image diagnosis}

Andreas Gegenfurtner, ${ }^{1}$ Ellen Kok, ${ }^{2}$ Koos van Geel, ${ }^{2}$ Anique de Bruin, ${ }^{2}$ Halszka Jarodzka, ${ }^{3}$ Adam Szulewski ${ }^{4}$ \& Jeroen JG van Merriënboer ${ }^{2}$

CONTEXT Visual expertise is the superior visual skill shown when executing domainspecific visual tasks. Understanding visual expertise is important in order to understand how the interpretation of medical images may be best learned and taught. In the context of this article, we focus on the visual skill of medical image diagnosis and, more specifically, on the methodological set-ups routinely used in visual expertise research.

METHODS We offer a critique of commonly used methods and propose three challenges for future research to open up new avenues for studying characteristics of visual expertise in medical image diagnosis. The first challenge addresses theory development. Novel prospects in modelling visual expertise can emerge when we reflect on cognitive and socio-cultural epistemologies in visual expertise research, when we engage in statistical validations of existing theoretical assumptions and when we include social and socio-cultural processes in expertise development. The second challenge addresses the recording and analysis of longitudinal data. If we assume that the development of expertise is a long-term phenomenon, then it follows that future research can engage in advanced statistical modelling of longitudinal expertise data that extends the routine use of cross-sectional material through, for example, animations and dynamic visualisations of developmental data. The third challenge addresses the combination of methods. Alternatives to current practices can integrate qualitative and quantitative approaches in mixed-method designs, embrace relevant yet underused data sources and understand the need for multidisciplinary research teams.

CONCLUSION Embracing alternative epistemological and methodological approaches for studying visual expertise can lead to a more balanced and robust future for understanding superior visual skills in medical image diagnosis as well as other medical fields.

Medical Education 2017: 51: 97-104

doi:10.1111/medu.13205

Discuss ideas arising from the article at www.mededuc.com discuss.

\footnotetext{
${ }^{1}$ Technische Hochschule Deggendorf, Deggendorf, Germany

${ }^{2}$ Maastricht University, Maastricht, the Netherlands

${ }^{3}$ Open University of the Netherlands, Heerlen, The Netherlands

${ }^{4}$ Queen's University, Kingston, Canada
}

Correspondence: Andreas Gegenfurtner, Institut für Qualität und Weiterbildung, Technische Hochschule Deggendorf, Edlmairstrasse 9, 94469, Deggendorf, Germany.

Tel: 00499913615 725; E-mail: andreas.gegenfurtner@th-deg.de 
INTRODUCTION

Medical students and laypersons are often amazed when an expert is able to correctly discern, with a single fixation in the range of milliseconds, if a medical image shows a normal case or a rare abnormality. ${ }^{1}$ This ability has also led expertise researchers to seek answers as to why some particularly skilled medical professionals are so accurate and efficient in medical image diagnosis, and even far more accurate than equally senior colleagues. ${ }^{2,3}$ Understanding this can provide much-needed insight into how we can optimally teach students and residents to reach this level of expertise.

Research groups worldwide have conducted many studies $^{4-12}$ to address and unveil the processes behind this impressive capacity. These reviews highlight the superior perceptual skills of visual experts, originating from their ability to selectively ignore irrelevant information, their ability to see medical images as patterns rather than separate pieces of unrelated information, and their ability to select appropriate diagnostic schemata to fit the observations. Medical visual expertise is defined as reproducibly superior visual skills when making a diagnosis from a medical image. ${ }^{6}$ In expertise studies, a comparison is often made between high performing professionals (e.g. consultant radiologists or cardiologists) and novices (e.g. students or laypeople). ${ }^{10,13}$ A medical image is defined as a visual representation of the human anatomy or its functions $^{2,11}$; examples of medical images include, but are not limited to, X-ray images, computer tomography or positron emission tomography scans, magnetic resonance images, ultrasonography, electrocardiograms, pathological slides, and photographs in clinical dermatology.

Medical images play an important role in everyday medical practice. In many medical disciplines, medical images are an important element of diagnostic reasoning. Thus, it is critical to have a good understanding of how visual diagnostic reasoning takes place, as errors made in diagnostic reasoning are a potential threat to patient safety. ${ }^{11,14}$ Yet, we have an incomplete understanding of characteristics of visual expertise, which can be attributed to the methods that have been routinely used in previous research. ${ }^{11}$ Although previous research has provided important insights into visual expertise in medical image diagnosis, it also left us with several blind spots.

This article will engage in a critical analysis of the routinely used methods in previous research on visual expertise in medical image diagnosis. This article will not review the available evidence on expertise processes; we omit a systematic review not because this literature is unimportant but because, as cited in the previous paragraph, excellent reviews exist on this topic already. ${ }^{4-12}$ By contrast, this article will deliberately take a methodological perspective on existing research and articulate three challenges that, in our opinion, are viable potential ideas for opening up new avenues when studying the processes of visual expertise in medicine. The first challenge centres on the development of theories to explain the superiority of visual experts. The second challenge highlights the need for advanced longitudinal analyses. The third challenge elaborates on the combination of methods for data collection. When we discuss each of the three challenges below, we will selectively reference sources outside the realms of health sciences education that we think can be important inspirations to help rethink some of the methodological practices found in studies addressing visual expertise in medicine.

\section{CHALLENGE 1: DEVELOPING THEORY}

According to Karl Popper's critical rationalism, ${ }^{15}$ a theory is developed through iterative empirical tests of its intrinsic assumptions. If an assumption is falsified, that assumption of the theory is revised. Empirical tests are always rooted in a given epistemology that indicates which methods are used to empirically falsify the given theoretical assumptions. We argue here that if we want to advance research on visual expertise in medicine, then we first and foremost need 'better' theories; the word 'better' here implies theories that are firmly rooted in epistemological groundings, that are open in addressing units of analysis beyond the individual mind and that have statistically validated assumptions.

First, we believe that it is a timely endeavour to study processes of visual expertise outside the classic arenas of cognitivism. Research in a cognitivist tradition has created numerous fascinating findings on cognitive differences between expert and non-expert populations. ${ }^{1-12}$ However, despite this rich body of valuable evidence, a limitation to a single epistemological set-up can restrict method practices unnecessarily, which in turn can hinder new forms of knowing about visual expertise. For instance, the vast majority of studies on visual expertise in medical image diagnosis used the individual as the level of analysis. Exemplary units of analysis are the 
number of fixations on the screen ${ }^{1,2,10}$ or the frequency of codes in think-aloud protocols. ${ }^{2,4,12}$ Level and unit of analysis thus reside within a cognitivist interpretation of perception and focus solely on the interaction between the brain and the eye. The ecological perspective of James Gibson ${ }^{16}$ looks beyond this, and stresses that visual expertise includes the skillful coordination of 'the body, the head, the eyes, the appurtenances of an eye (eyelid, pupil, and lens), and finally the retina of an eye which is composed of photocells and nerve cells'.

If we go one step further than James Gibson, then we can consider the visual system an expert uses as a system including the self, other human agents and non-human mediators. ${ }^{11,17-19}$ This is the perspective adopted by researchers in the tradition of Charles Goodwin, who was among the first to articulate that vision was more than just an individual activity.

Rather, visual expertise (or professional vision in the terms of Goodwin) is socially distributed and materially mediated. ${ }^{20}$ If we study visual expertise from a Goodwinian framework, then we embrace a socio-cultural perspective and interpretivist epistemology that informs us on the social processes that contribute to expert performance. ${ }^{18}$ Fascinating work from Daniel Koschmann and colleagues ${ }^{21,22}$ informs us that seeing is communicated, socially negotiated and mediated by tools and artifacts that are essential parts of the visual system..$^{2,11,18,23}$ To date, social and socio-cultural processes are too often neglected in studies on visual expertise in health sciences education, as are studies that adopt motivational, emotional and socio-emotional perspectives on expertise. Among the reasons for this neglect can be a certain historic preference for cognitively informed study designs with an individual level of analysis. This is surprising if we see that the early development of expertise is often nested within master-apprentice dyads, ${ }^{24}$ which is particularly true for visual expertise development in medical education.

Medical students or residents often discuss medical images with peers or medical doctors, for example during bedside teaching episodes. ${ }^{25}$ This interaction has not been investigated much so far. Even more so, in health care settings, care is not delivered by individuals, but by (master-apprentice) dyads and expert teams. If we wish to extend our understanding of visual expertise and the development of expert performance, then it is timely to consider alternative epistemological groundings that can offer an equally fascinating paradigm inter pares with cognitivism. Ultimately, we believe that the frontiers of visual expertise research will expand with studies that take the risk of combining paradigms; very few studies exist, to our knowledge, that combine the strengths of cognitivist and ecologist perspectives to show how skillfully expert clinicians orchestrate their eyes, their head, their body postures, gestures and tool manipulations when they interact with the visual material and with each other. This is especially true when considering expertise in medical fields outside of image diagnosis where the social context becomes even more important as physicians interact with one another as well as with nurses, allied health workers and patients themselves. ${ }^{11,26,27}$

Experts are by definition rare. As a consequence, when investigating expertise, studies are conducted with few participants only. This is problematic when drawing conclusions for theory development

because a small empirical basis for developing theories risks being biased from type A or type B errors. Behind these statistical error terms lies the problem of limited power that arises from the typical small sample size in expertise research. Gegenfurtner and colleagues ${ }^{10}$ showed that typical expertise studies have groups of up to 10 participants. Sampling errors are frequent problems and statistical corrections of sampling artifacts are rare. Possible remedies for the statistical validation of theoretical assumptions are replication and meta-analysis. In the health sciences, both remedies are rare (though meta-analyses on visual expertise exist in neighbouring disciplines). ${ }^{10,28,29}$ These remedies, however, could help us develop 'better' theories of visual expertise.

To summarise our first challenge, we argue that theories on visual expertise in medical image diagnosis should be based on a critical reflection of the epistemological assumptions behind the chosen methods, should address cognitive, motivational, social and sociocultural dimensions of professional knowing and seeing, and consider statistical validation of theoretical assumptions through replication and meta-analysis to help refine the conceptual beliefs of theory models through repeated attempts at falsification. ${ }^{15}$

CHALLENGE 2: COLLECTING AND ANALYSING LONGITUDINAL DATA

After these more epistemological thoughts on the underlying premises of theory development, we now come to a more practical concern. Expertise research is often cross-sectional. ${ }^{10,11}$ Because experts 
are by definition rare, researchers have often limited chances to gather a large number of expert professionals and follow their trajectories systematically over time. ${ }^{30}$ Whereas in other topics the importance of longitudinal follow-up is already acknowledged, the majority of studies on visual expertise still rely on cross-sectional snapshots. Why is this a problem and what can we do?

The development of expertise is a long-term phenomenon. The assumption behind cross-sectional research is that when we contrast individuals with high and low levels of expertise, we get a glimpse of how expertise in a given domain changes the cognitive capacities of individuals on their road towards expertise. ${ }^{10,11,13,31}$ Many theories have their empirical fundament in cross-sectional research. Here, we claim that if visual expertise research wishes to advance into more robust realms, more efforts are needed to follow individuals over time. ${ }^{11,30}$ This will provide a more fine-grained insight into the trajectory of change between the canonical 'novice' (e.g. a medical student or medically naïve layperson) and 'expert' (e.g. a very experienced consultant) groups. It might be particularly relevant to longitudinally follow residents, instead of focusing only on those 'extreme' points on the expertise scale. Residents will show a tremendous change over a couple of years that will provide insight into the timing of how different aspects of expertise develop. Specifically, do certain characteristics of experts develop before (and impact) other characteristics? For example, experts are more systematic than novices when inspecting radiographs. ${ }^{32}$ Should we interpret this as meaning that being systematic leads to higher performance? Based on a cross-sectional design, we can just as easily argue that a higher performance leads to experts being more systematic.

A longitudinal study could provide insight into whether a systematic approach develops before or after a resident shows improved performance. A longitudinal study could also follow those who are already highly experienced when they adapt to changing contextual affordances at their clinical workplace ${ }^{33}$; the rationale behind this suggestion is that 'experts' are not the end of the continuum, but they continue to develop, adapt and refine their skills. ${ }^{2,30,33}$ Once these data are collected, we call for advanced statistical modelling of these longitudinal expertise data. ${ }^{34-36}$ Although we do not wish to argue against the analysis of between-person effects as approximations for expertise, we do think that within-person effects will give rise to more advanced inferences on intra-individual differences ${ }^{36}$ that have the potential to falsify or revise existing theoretical models derived from cross-sectional data. Longitudinal data collections are not always easily accomplished because it can be a challenge to follow-up participants, find multi-year funding or take the risk of collecting different rounds of data with unforeseeable outcomes.

Along the lines of longitudinal data collection, a related advancement in longitudinal data analysis rests in the new opportunities of data visualisations. Many journals are now open to reporting two- and three-dimensional data renderings of, for example, time-series and panel data (multiple measures over multiple times for the same individuals). These options give rise to novel ways of analysing expertise data that have not existed (or were not systematically published) before. To achieve such dynamic visualisations and animations, we need to collect process data at multiple times. Related concerns about missing data arise, and on a more basal level, concerns about the methodological expertise of research teams who may be unfamiliar with the particularities of longitudinal statistical modelling. Despite these burdens, it is easy to appreciate the advantage of dynamic within-person data over static between-person data. Statistical techniques such as multilevel analysis have the potential to model data without being impacted strongly by missing data. $^{35,36}$

In summary, more longitudinal data collections and analyses represent a second challenge for the future of visual expertise research. When we solve the problems associated with recruiting participants, managing missing data and modelling time-related change, then our studies can result in finely tuned insights into the developmental trajectories of expertise development that add to the existing body of cross-sectional comparisons of participants with varying levels of expertise. In turn, these more finegrained accounts of how professional expertise develops over time can inform novel theory building or, at the very least, be useful for testing assumptions of existing conceptual frameworks built around evidence from cross-sectional data material. Importantly, this could provide information as to how to structure teaching in visual tasks for students and residents.

CHALLENGE 3: COMBINING METHODS

Whereas the first challenge addressed the development of theory and the second challenge focused 
on the collection and analysis of longitudinal data, the third challenge regards the nexus of theory and methods. We argue that if visual expertise research aims to develop in new directions, then we need to allow novel and unconventional combinations of methods to aggregate data material that transcends single paradigmatic boundaries. This would allow for a broader understanding of visual expertise, which so far has been dominated by the use of quantitative, mostly cognitively oriented, research methods. More specifically, we call for a productive combination of methods driven by innovative research questions. In addressing this challenge more deeply, this section details the benefits of integrating qualitative and quantitative data in mixedmethod designs, discusses relevant yet underused data sources and examines the need for multidisciplinary research teams.

Mixed-methods research is defined as the combination of qualitative and quantitative methods for collecting and analysing data. ${ }^{37}$ Examples of mixedmethods research in medical education can be found in previous publications. ${ }^{2,38-40}$ Grounded in the philosophical arena of pragmatism, mixed-methods research is often considered the third methodological movement bridging (i) quantitative and (ii) qualitative paradigms. ${ }^{41}$ Mixed-methods research combines the advantage of quantitative and qualitative research and should therefore advance the field of visual expertise research in new directions. ${ }^{40}$ More specifically, in expertise research, mixedmethod studies can result in stronger evidence because findings converge and are corroborated from quantitative and qualitative sources. ${ }^{2,42} \mathrm{By}$ combining methods, it is possible to use the strengths of one method to overcome the limitations of another method; this allows for answering broader and more complete research problems and thus a deeper inquiry into the processes of visual expertise. ${ }^{11}$ Put practically, using mixed-method designs means that verbal material (narratives) can be added to numeric material (statistics) and vice versa. This complementarity of approaches is likely to produce insights that would not be possible with mono-method designs. ${ }^{37}$ Consequently, a triangulation of the available evidence can produce more generalisable findings and ultimately a more complete picture of visual expertise that can be useful for theory building.

Within the context of medical image diagnosis, a typically found scenario for mixed-method studies is the combined analysis of verbal think-aloud data and eye tracking data. ${ }^{2}$ For example, a study using microscopic images of colon tissue ${ }^{42}$ illustrated that different visual and cognitive strategies can result in equal levels of diagnostic accuracy. Specifically, verbal analysis of the post-hoc explanations showed that expert participants verbalised the typicality of the visual material whereas intermediate participants verbalised a large number of pathologies. In addition, eye tracking data revealed that, once the abnormality was detected, expert participants scanned the visual material for additional findings whereas intermediate participants re-fixated on the originally detected abnormality to double-check. This combined analysis of eye tracking data and verbal data is interesting because it illustrates that different information-processing strategies can result in the same level of diagnostic accuracy. In order to understand those different strategies, and how they lead to the same level of diagnostic accuracy, a broader perspective on visual expertise is needed.

The combination of eye-tracking data and verbal data acknowledges that eye tracking data could provide information on subconscious visual processes that cannot be reported on, whereas verbal thinkaloud data could provide insight as to why people look where they do. ${ }^{2,11,43}$ Such an insight can have important implications for medical education because it might make it easier for clinical teachers to adapt their teaching to where students look, and cue them to direct their attention to other relevant information. ${ }^{44-46}$ The expert modelling of attentional resource allocation can also go beyond traditional classroom settings and inform the design of digital simulations ${ }^{4,45,47-49}$ to train and develop the visual skills of medical students and residents.

At the same time, we should not forget the risks of mixed-method designs, including a higher work effort, higher costs and more demands for the researcher, who needs to be able to analyse different kinds of data. ${ }^{37,38}$ Furthermore, differences in temporal resolution and the units of analysis mean that a completely integrated analysis, which is desirable, is not always feasible. However, the combination of methods is a very promising way to generate novel insights into what constitutes visual expertise in medical image diagnosis (and other medical fields), although this also requires methodological research on the combination of data from several sources.

The combination of methods can also include considerations of relevant yet underused data sources. More specifically, with regard to visual expertise studies, typically used data formats are performance 
data, verbal reports, observations or the tracking of eye movements. ${ }^{11}$ In addition to these sources of data, other interesting approaches for data collection include $\log$ files, functional magnetic resonance imaging (fMRI), pupillometry and network analysis. First, log files are frequently used in domains outside health science education to better understand participant expertise. For example, in word-processing tasks, Vaubel and colleagues ${ }^{50}$ analysed key metrics such as help requests to explain higher levels of expertise. In medical education, Jaarsma and colleagues ${ }^{51}$ logged navigation through pathological slides to explain experts' superior levels of efficiency. Similar analyses are possible for examining how expert users interact with digital devices used for creating graphical representations of the human body or its functions. Besides log data, fMRI also provides a novel and promising way of generating new data to trace visual expertise. It promises to provide insight into brain areas that might be involved in visual expertise.

The use of brain scans as a way to further understand differences in expertise in medicine is in its infancy, yet these scans can be useful for examining qualitative differences in comprehension. For instance, Harley and colleagues ${ }^{52}$ used fMRI to investigate how expertise in radiology impacts brain activation patterns. They noted that achieving expert visual performance might involve suppressing existing neural representations while simultaneously developing others. This could be interpreted as meaning that experts are not doing the same task better, but using different cognitive processes for the same task. A third data source that is relevant but yet underused for examining visual expertise is pupillometry. Specifically, pupil size has been found to be a good marker of cognitive load. ${ }^{27}$ In a study by Szulewski and colleagues, ${ }^{26}$ physicians' taskevoked pupillary responses (TEPRs) have been found to correlate with changes in cognitive processing demands during medical test-taking. Finally, network analyses could visualise patterns of communication within health care teams, and would allow research to go beyond the individual level of analysis. ${ }^{53}$ Certainly, there are many more data sources that can be used to investigate how expert clinicians diagnose medical images, and log data, fMRI, pupillometry and network analysis are mere examples that can be used to create non-routine data material for studying visual expertise.

Combining qualitative and quantitative methods or collecting relevant yet underused data both indicate that the methodological demands on the researcher and the research group are growing. To cover these increasing demands, we recommend creating interdisciplinary teams that include experts from different arenas. Interdisciplinary teams can also be useful for creating new theoretical models because communication across one's typical work domain includes the need to cross disciplinary boundaries. Of course, multidisciplinary teams are not only beneficial for collecting and analysing data or for modelling theoretical assumptions. Such teams are also an asset for any research project on the nexus between education, psychology, computer sciences and the health sciences, largely because a research plan that passed the critical eyes of members from different professional groups can result in useinspired fundamental research. Thus, theory building as well as educational practice in clinical settings can be of benefit, particularly when research groups from different domain-specific 'islands' note the relevance and resemblance of related work outside their domain-specific boundaries. Despite these positive outlooks, Engeström and colleagues ${ }^{54}$ indicate that collaboration in interdisciplinary work teams can be conflicting as well, leading to non-productive output and errors.

To summarise the third challenge, we call for more research projects that combine data sources and analysis methods through integrating qualitative and quantitative methods in mixed-method designs, that make use of data sources that are currently unusual in studying expertise within health sciences (log files, fMRI and pupillometry), and that engage in the efforts to create multidisciplinary research teams.

\section{CONCLUSION}

Is there a future for visual expertise research? This article set out to discuss three challenges in studying visual expertise research in the health sciences. These challenges are presented as potential avenues to be followed in further studies in an attempt to create a more balanced and robust future for visual expertise research. This will increase our understanding of visual expertise and, most importantly, how to foster it in our students and residents. First, we believe this future can be more balanced because the current bias toward cognitive methodologies and individuals as units of analysis can be counterbalanced with an increase of studies employing alternative epistemologies or conceptions of visual perception. ${ }^{17}$ It can also be more balanced by the use of qualitative and quantitative methods, as 
this will give rise to a triangulation of data pools that can stimulate theorising of visual expert processes.

Furthermore, we believe this future can be more robust because communication in multidisciplinary research teams can help eliminate potential sources of error when planning the study. Longitudinal analyses will help corroborate or revise existing theoretical models that are based on cross-sectional data. Similarly, examination of social and sociocultural processes will complement the study of cognitive mechanisms and yield a more complete understanding of the many facets of visual expertise in medical image diagnosis, and potentially other medical fields as well.

Contributions: all authors contributed substantially to the conception of the paper, drafted and revised the manuscript, and approved the final version of the revised manuscript. We all agree to be accountable for all aspects of the paper.

Acknowledgements: none.

Funding: none.

Conflicts of interest: none.

Ethical approval: not applicable.

\section{REFERENCES}

1 Bertram R, Helle L, Kaakinen JK, Svedstrom E. The effect of expertise on eye movement behaviour in medical image perception. PLoS One 2013;8 (6): e66169.

2 Gegenfurtner A, Seppänen M. Transfer of expertise: an eye-tracking and think-aloud study using dynamic medical visualizations. Comput Educ 2013;63 (1):393403.

3 Balslev T, Jarodzka H, Holmqvist K, de Grave W, Muitjens AM, Eika B, van Merriënboer JJG, Scherpbier AJ et al. Visual expertise in paediatric neurology. Eur J Paediatr Neurol 2012;16 (2):161-6.

4 Norman GR, Coblentz CL, Brooks LR, Babcook CJ. Expertise in visual diagnosis - a review of the literature. Acad Med 1992;67 (10):S78-S83.

5 Wood BP. Visual expertise. Radiology 1999;211 (1):1-3.

6 Ericsson KA. Deliberate practice and the acquisition and maintenance of expert performance in medicine and related domains. Acad Med 2004;79 (10 Suppl): S70-81.

7 Norman G, Eva KW, Brooks LR, Hamstra S. Expertise in medicine and surgery. In: Ericsson KA, Charness N, Feltovich P, Hoffman RR, eds. The Cambridge Handbook of Expertise and Expert Performance. Cambridge: Cambridge University Press 2006;339-53.

8 Krupinski EA. Current perspectives in medical image perception. Atten Percept Psychophys 2010;72 (5):1205-17.
9 Reingold EM, Sheridan H. Eye movements and visual expertise in chess and medicine. In: Leversedge SP, Gilchrist ID, Everling S, eds. Oxford Handbook on Eye Movements. Oxford: Oxford University Press 2011;528-50.

10 Gegenfurtner A, Lehtinen E, Säljö R. Expertise differences in the comprehension of visualizations: a meta-analysis of eye-tracking research in professional domains. Educ Psychol Rev 2011;23 (4):523-52.

11 Gegenfurtner A, Siewiorek A, Lehtinen E, Säljö R. Assessing the quality of expertise differences in the comprehension of medical visualizations. Vocat Learn 2013;6 (1):37-54.

12 Kok EM. Developing visual expertise: From Shades of Grey to Diagnostic Reasoning in Radiology [Dissertation].

Maastricht: University Press Maastricht 2016.

13 Chi MTH, Glaser R, Farr MJ, eds. The Nature of Expertise: Hillsdale. NJ: Erlbaum 1988.

14 Graber ML, Wachter RM, Cassel CK. Bringing diagnosis into the quality and safety equations. JAMA 2012;308 (12):1211-2.

15 Popper K. All Life is Problem Solving. New York: Psychology Press 1999.

16 Gibson JJ. The Ecological Approach to Visual Perception. New York: Psychology Press 1986.

17 Jarodzka H, Jaarsma T, Boshuizen HPA. In my mind: how situation awareness can facilitate expert performance and foster learning. Med Educ 2015;49 (9):854-6.

18 Säljö R. Learning, theories of learning, and units of analysis in research. Educ Psychol 2009;44 (3):202-8.

19 Van Merriënboer JJG, de Bruin ABH. Research paradigms and perspectives on learning. In: Spector MJ, Merrill DM, Elen J, Bishop JM, eds. Handbook of Research on Educational Communications and Technology. New York: Springer 2014;21-9.

20 Goodwin C. Professional vision. Am Anthropol 1994;96 (3):606-33.

21 Koschmann T, LeBaron C, Goodwin C, Feltovich P. "Can you see the cystic artery yet?" A simple matter of trust. J Pragmat 2011;43 (2):521-41.

22 Zemel A, Koschmann T. 'Put your fingers right in here': learnability and instructed experience. Discourse Stud 2014;16 (2):163-83.

23 Lindwall O, Johansson E, Rystedt H, Ivarsson J, Reit C. The use of video in dental education: clinical reality addressed as practical matters of production, interpretation and instruction. In: Broth M, Laurier E, Mondada L, eds. Studies of Video Practices: Video at Work. New York: Routledge 2014;161-80.

24 Lave J. Apprenticeship in Critical Ethnographic Practice. Chicago: University of Chicago Press 2011.

25 Saha A, Roland RA. Radiology medical student education: an outcome-based survey of PGY-1 residents. Acad Radiol 2013;20 (3):284-9.

26 Szulewski A, Roth N, Howes D. The use of taskevoked pupillary response as an objective measure of cognitive load in novices and trained physicians: a new tool for the assessment of expertise. Acad Med 2015;90 (7):981-7. 
27 Szulewski A, Gegenfurtner A, Howes D, Sivilotti M, Van Merriënboer JJG. Measuring physician cognitive load: Validity evidence for a physiologic and a psychometric tool. Adv Health Sci Educ 2016 In press. doi:10.1007/s10459-016-9725-2

28 Mann DT, Williams AM, Ward P, Janelle CM. Perceptual-cognitive expertise in sport: a metaanalysis. J Sport Exerc Psychol 2007;29 (4):457.

29 Gegenfurtner A, Szulewski A. Visual expertise and the Quiet Eye in sports - comment on Vickers. Curr Issues Sport Sci 2016;1 (1):108.

30 Gegenfurtner A. Transitions of expertise. In: Seifried J, Wuttke E, eds. Transitions in Vocational Education. Opladen: Budrich 2013;305-19.

31 Chi MTH. Two approaches to the study of experts' characteristics. In: Ericsson KA, Charness N, Feltovich $\mathrm{P}$, Hoffman RR, eds. The Cambridge Handbook of Expertise and Expert Performance. Cambridge: Cambridge University Press 2006;21-30.

32 Kok EM, Jarodzka H, de Bruin AB, BinAmir HA, Robben SG, van Merrienboer JJG. Systematic viewing in radiology: seeing more, missing less? Adv Health Sci Educ Theory Pract 2015;21 (1):189-205.

33 Lehtinen E. Learning of complex competences: on the need to coordinate multiple theoretical perspectives. In: Koskensalo A, Smeds J, de Cillia R, Huguet À, eds. Language: Competencies - ChangeContact. Berlin: LIT 2012;13-27.

34 Boccignone G. Advanced statistical methods for eye movement analysis and modeling: a gentle introduction. arXiv preprint arXiv:150607194. 2015.

35 Leppink J. Data analysis in medical education research: a multilevel perspective. Perspect Med Educ 2015;4 (1):14-24.

36 McArdle JJ. Latent variable modeling of differences and changes with longitudinal data. Annu Rev Psychol 2009;60 (1):577-605.

37 Teddlie C, Tashakkori A. Foundations of Mixed-Methods Research: Integrating Qualitative and Quantitative Techniques in the Social and Behavioral Sciences. Thousand Oaks, CA: Sage 2008.

38 Lavelle E, Vuk J, Barber C. Twelve tips for getting started using mixed methods in medical education resear ch. Med Teach 2013;35 (4):272-6.

39 Maudsley G. Mixing it but not mixed-up: mixed methods research in medical education (a critical narrative review). Med Teach 2011;33 (2):e92-104.

40 Schifferdecker KE, Reed VA. Using mixed methods research in medical education: basic guidelines for researchers. Med Educ 2009;43 (7):637-44.

41 Johnson RB, Onwuegbuzie AJ. Mixed methods research: a research paradigm whose time has come. Educ Res 2004;33 (7):14-26.

42 Jaarsma T, Jarodzka H, Nap M, van Merrienboer JJG, Boshuizen HPA. Expertise under the microscope: processing histopathological slides. Med Educ 2014;48 (3):292-300.

43 Van Gog T, Kester L, Nievelstein F, Giesbers B, Paas F. Uncovering cognitive processes: different techniques that can contribute to cognitive load research and instruction. Comput Hum Behav 2009;25 (2):325-31.

44 Seppänen M, Gegenfurtner A. Seeing through a teacher's eyes improves students' imaging interpretation. Med Educ 2012;46 (11):1113-4.

45 Jarodzka H, Balslev T, Holmqvist K, Nyström M, Scheiter K, Gerjets P, Eika B. Conveying clinical reasoning based on visual observatio $\mathrm{n}$ via eyemovement modelling examples. Instr Sci 2012;40 (5):813-27.

46 Jarodzka H, Van Gog T, Dorr M, Scheiter K, Gerjets $\mathrm{P}$. Learning to see: guiding students' attention via a Model's eye movements fosters learning. Learn Instr 2013;25 (1):62-70.

47 Gegenfurtner A, Quesada-Pallarès C, Knogler M. Digital simulation-based training: a meta-analysis. $\mathrm{Br} \mathrm{J}$ Educ Technol 2014;45 (6):1097-114.

48 Helle L, Nivala M, Kronqvist P, Gegenfurtner A, Björk P, Säljö R. Traditional microscopy instruction versus process-oriented virtual microscopy instruction: a naturalistic experiment with control group. Diagn Pathol 2011;6 (S1):S81-9.

49 Siewiorek A, Gegenfurtner A, Lainema T, Saarinen E, Lehtinen E. The effects of computer-simulation game training on participants' opinions on leadership styles. Br J Educ Technol 2013;44 (6):1012-35.

50 Vaubel KP, Gettys CF. Inferring user expertise for adaptive interfaces. Hum-Comput Interact 1990;5 (1):95-117.

51 Jaarsma T, Boshuizen HPA, Jarodzka HPA, Nap M, Verboon P, Van Merrienboer JJG. Tracks to a medical diagnosis: expertise differences in visual problem solving. Appl Cogn Psychol 2016;30 (2):314-22.

52 Harley EM, Pope WB, Villablanca JP, Mumford J, Suh R, Mazziotta JC, Enzmann D, Engel SA Engagement of fusiform cortex and disengagement of lateral occipital cortex in the acquisition of radiological expertise. Cereb Cortex 2009;19 (11):2746-54.

53 Hommes J, Rienties B, de Grave W, Bos G, Schuwirth L, Scherpbier A. Visualising the invisible: a network approach to reveal the informal social side of student learning. Adv Health Sci Educ Theory Pract 2012;17 (5):743-57.

54 Engeström Y, Engeström R, Kärkkäinen M. Polycontextuality and boundary crossing in expert cognition: learning and problem solving in complex work activities. Learn Instr 1995;5 (4):319-36.

Received 15 February 2016; editorial comments to author 22 April 2016, accepted for publication 15 August 2016 